\title{
Diagnostic potential of Brucella melitensis Rev1 native Omp28 precursor in human brucellosis
}

\author{
ISMAIL KOYUNCU ${ }^{1}$, ABDURRAHMAN KOCYIGIT ${ }^{2}$, AHMET OZER ${ }^{3}$, SAHABETTIN SELEK ${ }^{2}$, \\ ADNAN KIRMIT ${ }^{l}$, HASAN KARSEN ${ }^{4}$
}

${ }^{1}$ Harran University, School of Medicine, Department of Medical Biochemistry, Şanliurfa, Turkey

${ }^{2}$ Bezmialem Vakif University, School of Medicine, Department of Medical Biochemistry, Istanbul, Turkey

${ }^{3}$ Harran University, School of Medicine, Department of Medical Genetics, Şanliurfa, Turkey

${ }^{4}$ Harran University, School of Medicine, Department of Infectious Diseases and Clinical Microbiology, Şanliurfa, Turkey

\begin{abstract}
Serologic tests for brucellosis aim to detect antibodies produced against membranous lipopolysaccharide of bacteria. Diagnostic use of this method is limited due to false positiveness. This study evaluates an alternative antigen to lipopolysaccharides (LPS), outer membrane 28-precursor-protein, of Brucella melitensis Rev1 for its diagnostic value. Omp28 precursor of B. melitensis Rev1 was cloned, expressed, and purified. 6-His and sumo epitope tags were used to tag the protein at N-termini. Omp28 gene was amplified based on the ORF sequence and cloned into a pETSUMO vector. The recombinant construct was propagated in Escherichia coli One Shot ${ }^{\circledR}$ Mach1 TM cells then transformed into E. coli BL21(D3) cells for protein expression. The purified protein was studied in an indirect ELISA for diagnosis of brucellosis. Sera samples from 60 patients were screened by ELISA and the results were compared to Rose Bengal plate test. Recombinant antigen-based iELISA has given a successful outcome with the sensitivity, specificity, positive predictive value, and negative predictive value of $87.8 \%, 96.2 \%, 96.6 \%$, and $78.78 \%$, respectively. In conclusion, recombinant production and purification of the immunodominant Omp28 precursor protein has been achieved successfully in a one-step process with efficient yield and can be used for diagnosis of brucellosis in humans.
\end{abstract}

Key words: ELISA, brucellosis, purification, recombinant Rev1, SUMO fusion, Omp28.

(Centr Eur J Immunol 2018; 43 (1): 81-89)

\section{Introduction}

Brucella spp. are a group of facultative intracellular bacteria that parasitise humans and many animal species $[1,2]$. More than half a million new cases of human brucellosis are reported annually in the world [3]. Due to the challenging nature of the disease course and some problems in diagnosis, brucellosis remains a major human public-health problem, especially in rural communities in many countries. Chronic infections in humans with Brucella melitensis are common [4, 5], and the incidence of brucellosis in livestock is an economic burden due to decreased productivity, increased animal loss, and weak offspring as well as having a crucial impact on the trade and export of livestock. Human brucellosis has a chronic course characterised by fever, chills, and malaise, requiring six weeks of therapy with at least two appropriate anti- biotics to achieve a cure [6]. The primary method of the diagnosis is still bacteriological isolation, but the culture has some drawbacks, including low rate of isolation success, no availability for immediate results, and burdensome processing of large numbers of samples making bacterial culture a low throughput method. Thus, in medical practice serological tests are primarily used for diagnosis of brucellosis. Classical serological techniques rely mainly on the detection of antibodies to lipopolysaccharide (LPS), a large endotoxin molecule residing on the outer membrane of the bacteria [7]. Serological tests, established on a principle of the demonstration of specific antibodies against the bacterial components, are used widely in the field for the diagnosis of brucellosis as an alternative to culture. The most popular ones are the Rose Bengal plate agglutination test (RBPT) and the standard tube agglutination test [8].

Correspondence: Ismail Koyuncu, PhD, Assist. Prof., Harran University, School of Medicine, Department of Medical Biochemistry, Osmanbey Kampusu Yerleşkesi, Tip Fakultesi Hastanesi, Tibbi Biyokimya Ad, Haliliye, 63020 Şanliurfa, Turkey, e-mail: ismailkoyuncu1@ gmail.com Submitted: 1.12.2016; Accepted: 10.03.2017 
High cross-reaction rates against several Gram-negative bacteria including Yersinia enterocolitica O:9, Eschericia coli O:116/O157, Salmonella urbana, Francisella tularensis, and Vibrio cholerae form the major clinical limitation of smooth form lipopolysaccharides (S-LPS), although it is still widely used due to its high immunogenicity and strong antigenicity [9-11]. Cross-reactions are the reason for false-positive results creating difficulties in accurate diagnosis of brucellosis [12]. In the literature, many studies have been conducted to overcome cross-reaction-related problems, aiming to identify alternative candidate diagnostic antigens evoking specific immune response. Various membranous, cytoplasmic, and periplasmic proteins have been identified as immunoreactive molecules [13-20]. Identification of outer membrane proteins (OMPs) of Brucella sp. was made in the last quarter of the $20^{\text {th }}$ century [21]. Since then, they have been found to be potential antigenic components possessing strong immunogenic and protective effects $[22,23]$. One of them, OMP28 precursor, is a periplasmic immunodominant antigen used as a target molecule evoking the production of anti-Brucel$l a$ antibodies for detection [24, 25].

In addition to the advantage of being in a field-usable format, ELISA provides high sensitivity and specificity, especially with the use of highly specific recombinant antigens like OMPs [26]. To further improve the specificity and sensitivity of ELISA, very pure immunoreactive bacteria-specific antigens are required. For this purpose, synthesis and assaying of the recombinant OMP28 (rOMP28) precursor protein were targeted. In the present study we described expression and purification of B. melitensis Rev1 OMP28 precursor protein in a generally accepted bacterial expression system, and addressed the diagnostic potential of the purified recombinant protein for screening human sera collected in a rural area.

\section{Material and methods}

\section{Bacterial strains and chemicals}

Brucella melitensis Rev1 vaccine strain (Biovar 1) was obtained from Dollvet (Veterinary Vaccine, Medicine, Biological Article Generation Industry and Trade Inc., Sanliurfa/Turkey). Escherichia coli One Shot ${ }^{\circledR}$ Mach1T1RTM served for cloning and plasmid amplification. E. coli BL21 (DE3) served as the expression host. Bacterial strains were stored at $-80^{\circ} \mathrm{C}$ until the time of use. Champion ${ }^{\mathrm{TM}} \mathrm{pET}$ SUMO Protein Expression System was purchased from Invitrogen, USA. GenElute ${ }^{\mathrm{TM}}$ Plasmid Miniprep Kit, Lysozyme from chicken egg white, dNTP Mix, Taq DNA Polymerase, ampicillin, kanamycin sulphate, and albumin from bovine serum (BSA) were purchased from SigmaAldrich, USA. Antigen of RBPT was obtained from Pendik Veterinary Control and Research Institute. Ni-NTA colon was purchased from Thermo (USA).

\section{Serum samples}

A total of 60 patient samples collected from local hospitals and 30 control samples from asymptomatic healthy voluntary donors were used in this study. All participants were informed about the experimental procedures, and their signed consents were obtained. All the procedures were approved by the Ethics Committee of the Harran University according to the principles of the Declaration of Helsinki.

\section{Genomic DNA extraction}

Genomic DNA from the inactivated $(0.5 \%$ formaldehyde) B. melitensis Rev1 strain grown in Trypticase Soy Broth was purified using GF-1 Bacterial DNA Extraction Kit (Vivantis, Malaysia) as recommended by the manufacturer and analysed by separation in $1 \%$ agarose gel electrophoresis. DNA concentration and purity were determined by spectral absorbance. All samples were stored at $-80^{\circ} \mathrm{C}$ until use.

\section{Cloning into pETSUMO expression vector}

Brucella melitensis Rev1 gene was amplified by PCR. The target region encoding the OMP28 precursor gene consisting of $753 \mathrm{bp}$ was amplified using specific primers designed based on the $B$. melitensis Rev 1 gene sequence recorded in the GenBank database with accession number AY634231.1 (forward: 5'-ACATTGGATCCATGAACACTCGTGCTAGC-3') (reverse: 5'-CGGCCAAGCTTTTACTTGATTTCAAAAACGACA-3'). PCR conditions were: hot start at $94^{\circ} \mathrm{C}$ for $3 \mathrm{~min}$, followed by 30 cycles of denaturation at $94^{\circ} \mathrm{C}$ for $3 \mathrm{~min}$, annealing at $65^{\circ} \mathrm{C}$ for $45 \mathrm{sec}$, and extension at $72^{\circ} \mathrm{C}$ for $1 \mathrm{~min}$. Then a final extension step of $10 \mathrm{~min}$ at $72^{\circ} \mathrm{C}$ was performed. PCR product was cloned into the pETSUMO expression vector possessing cloning and expression vectors, in which a recombinant protein includes a six-histidine and sumo tag at the $\mathrm{N}$-terminal end for easier purification and SUMO protease activation. The resulting construct was transformed into competent One Shot ${ }^{\circledR}$ Mach1 E. coli (Invitrogen, USA) host cells. Kanamycin-resistant colonies were grown until $\mathrm{OD}_{600}=0.5$ in $\mathrm{LB}$ medium containing $50 \mu \mathrm{g} / \mathrm{ml}$ of kanamycin, at $37^{\circ} \mathrm{C}$ with agitation. Sequencing-based verification for the integrity and the orientation of the newly synthesised amplicon was done by a genetic analyser (ABI PRISM ${ }^{\circledR} 310$ Genetic Analyzer). The recombinant plasmid (pETSUMO-OMP28 precursor) was then transformed into E. coli One Shot ${ }^{\circledR}$ BL21(DE3) (Invitrogen, USA) host cells.

\section{Expression of His-SUMO-OMP28 precursor fusion protein}

An overnight culture of the E. coli One Shot ${ }^{\circledR}$ BL21 (DE3) that harboured pETSUMO-OMP28 precursor expressing the OMP28 precursor protein with poly-His tag and SUMO fusion was diluted at $1: 50$ in 0.51 fresh LB 
broth containing $50 \mu \mathrm{g} / \mathrm{ml}$ kanamycin, and grown at $37^{\circ} \mathrm{C}$ with vigorous shaking $(250 \mathrm{rpm})$ as reported by Liu et al. in a technically similar approach [27]. When $\mathrm{OD}_{600}$ reached 0.5 , the expression of the pETSUMO-OMP28 precursor recombinant protein was induced by adding $1 \mathrm{mM}$ IPTG for an additional six hours at $37^{\circ} \mathrm{C}$ shaken at $300 \mathrm{rpm}$. The cells were washed in $10 \mathrm{mM}$ sodium phosphate buffer $(\mathrm{pH} 8.0)$ and collected by centrifugation at $6000 \mathrm{~g}$ for $20 \mathrm{~min}$. Cell pellets were stored at $-20^{\circ} \mathrm{C}$.

\section{Purification of SUMO fusion protein}

His-SUMO-OMP28 precursor fusion protein was purified by immobilised nikel affinity chromatography (Ni-NTA, Thermo). The frozen cells were taken to room temperature (RT), lysozyme $(1 \mathrm{mg} / \mathrm{ml})$ was added and the mixture was left for $30 \mathrm{~min}$ on ice. Samples were lysed with cold denaturing lysis buffer $\left(100 \mathrm{mM} \mathrm{NaH} \mathrm{PO}_{4}\right.$, $8 \mathrm{M}$ urea, $1 \%$ tritonX-100, $10 \mathrm{mM}$ imidasole and Tris-HCI [pH 8.0]) with stirring for $10 \mathrm{~min}$ at RT and was then subjected to a sonication step (40\% range, 10-sec impulse, and 10 -sec pauses). The sonicated samples were centrifuged at $10,000 \mathrm{rpm}$ for $30 \mathrm{~min}$. The recombinant fusion protein within clarified supernatant was loaded onto a Ni-NTA resin affinity chromatography column equilibrated with binding buffer $(10 \mathrm{mM}$ imidazole, $8 \mathrm{M}$ urea (1\% triton $\mathrm{X}-100, \mathrm{PBS}, \mathrm{pH}$ 7.4). Nonspecific binding was washed away. After three cycles of washing (20 mM imidazole, $8 \mathrm{M}$ urea, triton X-100 1\%, PBS, pH 7.4), the fusion protein was eluted with adequate volumes of elution buffer (300 mM imidazole, $8 \mathrm{M}$ urea, triton X-100 1\%, PBS, $\mathrm{pH}$ 7.4). After the purification step, the urea was removed using dialyse with a decreasing concentration of urea in a linear gradient from 6 to $0 \mathrm{M}$, and the recombinant protein was eluted with imidazole gradient $(0-0.5 \mathrm{M})$ in a sodium phosphate buffer $(20 \mathrm{mM}, \mathrm{pH} 8.0)$. By this process, the protein could shape its native form by folding.

\section{SDS-PAGE, Western blotting, and protein determination}

The expressed recombinant protein was purified by Ni-NTA chromatography, separated on SDS-PAGE, and confirmed with western blot analysis using anti-his antibody [28, 29]. In brief, following separation of the cell extracts on $12 \%$ SDS-PAGE and staining with Coomassie Blue, the recombinant protein samples were transferred to PVDF membrane (Sigma-Aldrich) blocked with $1 \%$ BSA in PBST (PBST/BSA, pH 7.4, 0.1\% Tween 20). The membrane strips were then incubated with monoclonal anti-His-tag antibody with gentle shaking at a dilution of $1: 5000$ for $1 \mathrm{~h}$ at RT. Alkaline phosphatase (AP)-conjugated goat anti-mouse $\gamma$-chain specific antibody (SigmaAldrich) solution was then applied for $1 \mathrm{~h}$ at RT with shaking. As soon as a colour reaction was observed with the addition of BCIP/NBT, the reaction was ceased by adding a stop solution. Protein concentration was determined by the Bradford method spectrophotometrically at $595 \mathrm{~nm}$ [30].

\section{Cleavage-driven separation of SUMO fusion protein and target protein purification}

The dialysed fusion protein was subjected to SUMO protease treatment $\left(1 \mathrm{U}\right.$ per $50 \mu \mathrm{g}$ fusion protein) at $30^{\circ} \mathrm{C}$ for 1 hour as reported by Wang et al. [31]. By subtracting the $6 \times$ His-tagged proteins, which are both SUMO and SUMO protease, we purified and eluted OMP28 precursor by nickel column with Ni-NTA resin. Acquired proteins with high-UV values, as desired at $\mathrm{A}_{280}$, were collected. The purified proteins were run on SDS-PAGE and stored at $-80^{\circ} \mathrm{C}$ for iELISA assay.

\section{Agglutination assays for antibody detection}

The standard method for RBPT on glass plate was followed [8]. Sera samples and antigen were brought to RT $30 \mu \mathrm{l}$ of antigen and $30 \mu \mathrm{l}$ of serum were loaded on a glass slide and mixed thoroughly. Any degree of agglutination visible within 3 min was considered as a positive sera sample.

\section{iELISA with purified OMP28 precursor}

Serum samples were quantified if an antibody activity was present via an indirect microplate IgG ELISA (iELISA), and the method was standardised using newly purified OMP28 precursor as described by Liu et al. [27]. In detail, 96-well polystyrene plates (Corning, Corning, NY, USA) were loaded with the purified OMP28 precursor protein diluted in carbonate-bicarbonate buffer $(25 \mathrm{mM}$, $\mathrm{pH} 9.6)$ at a concentration of $20 \mu \mathrm{g} / \mathrm{ml}, 100 \mu \mathrm{l} /$ well and incubated overnight at $4{ }^{\circ} \mathrm{C}$ for coating. Emptied and washed with $10 \mathrm{mM}$ phosphate-buffered saline $-0.05 \%$ Tween 20 (PBST), the wells were then blocked with a solution of PBST and 2\% BSA (Sigma) to prevent nonspecific binding sites, followed by PBST wash. Serum samples, $100 \mu \mathrm{l}$ in volume, at a dilution of $1: 100$ in PBST-BSA, were transferred to the wells in duplicate including positive and negative serum samples and PBST-empty controls. The plate was incubated for $60 \mathrm{~min}$ at $37^{\circ} \mathrm{C}$, then washed again and filled with $100 \mu$ of HRP-conjugated goat antihuman IgG diluted 1: 1000 in a solution of PBST-BSA. Incubation for $60 \mathrm{~min}$ at $37^{\circ} \mathrm{C}$ with primary antibody was followed by the discarding the plate content and washing with PBST. $100 \mu \mathrm{l}$ of the HRP substrate working solution was prepared immediately before use, as follows: $100 \mu \mathrm{l}$ of TMB-A and TMB-B stock solution was added. Colour development was visualised at $37^{\circ} \mathrm{C}$ for $8-10 \mathrm{~min}$ in the dark, and the reaction was stopped by adding stop solution made by $50 \mu \mathrm{l} 2 \mathrm{M} \mathrm{H}_{2} \mathrm{SO}_{4}$. The plate was read at $450 \mathrm{~nm}$ with an ELISA reader (Spectra M5). The cutoff value of OMP28 precursor-iELISA system was calculated as the mean specific $\mathrm{OD}_{450} \mathrm{~nm}$ of control (negative) sera plus threefold standard deviation (SD). 


\section{Evaluation of sensitivity and specificity of OMP28 precursor-iELISA}

In relation to well-established RBPT, the sensitivity and specificity of rOMP28 precursor-iELISA were calculated using test samples including human Brucella-positive and Brucella-negative sera ( $n=30$ /group), as described by Fawcett [32].

\section{Results}

\section{Amplification, cloning, and sequencing of the OMP28 precursor gene}

The amplification of OMP28 precursor gene formed a main fragment of approximately $753 \mathrm{bp}$. Using a highly effective combined cloning-expression vector employing
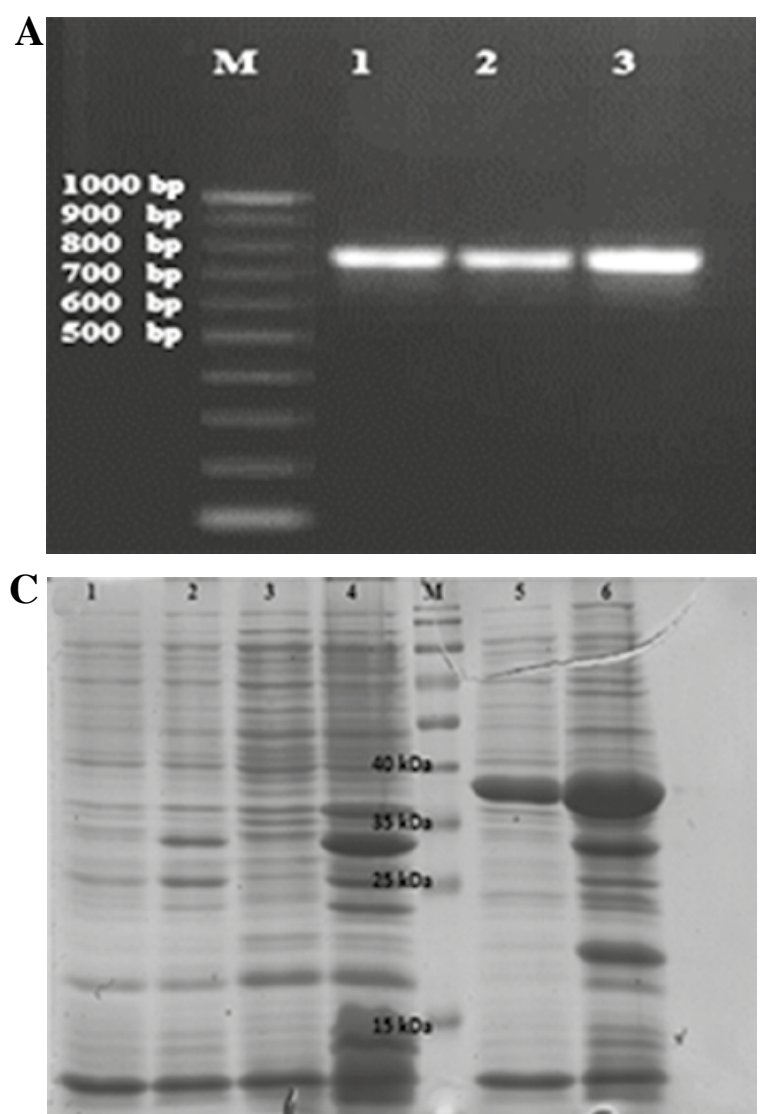

a direct $\mathrm{A} / \mathrm{T}$ cloning method, the PCR product was cloned successfully in the pETSUMO expression vector. The integrity of the constructed vector pETSUMO-OMP28 precursor was confirmed by using specific primers with PCR. The PCR fragments were loaded on $1 \%$ agarose gel, stained with EtBr, and visualised using a gel documentation system. Specific bands matched the corresponding size of the OMP28 precursor (Fig. 1A). The nucleotide sequence of the cloned product was confirmed with a perfect match with the reported sequence of the OMP28 precursor gene for B. melitensis Rev1 (GenBank accession no. AY634231.1).

\section{Expression and purification of the recombinant His-SUMO-OMP28 precursor fusion protein}

We achieved high quality expression of His-SUMOOMP28 precursor protein. The results suggested that an
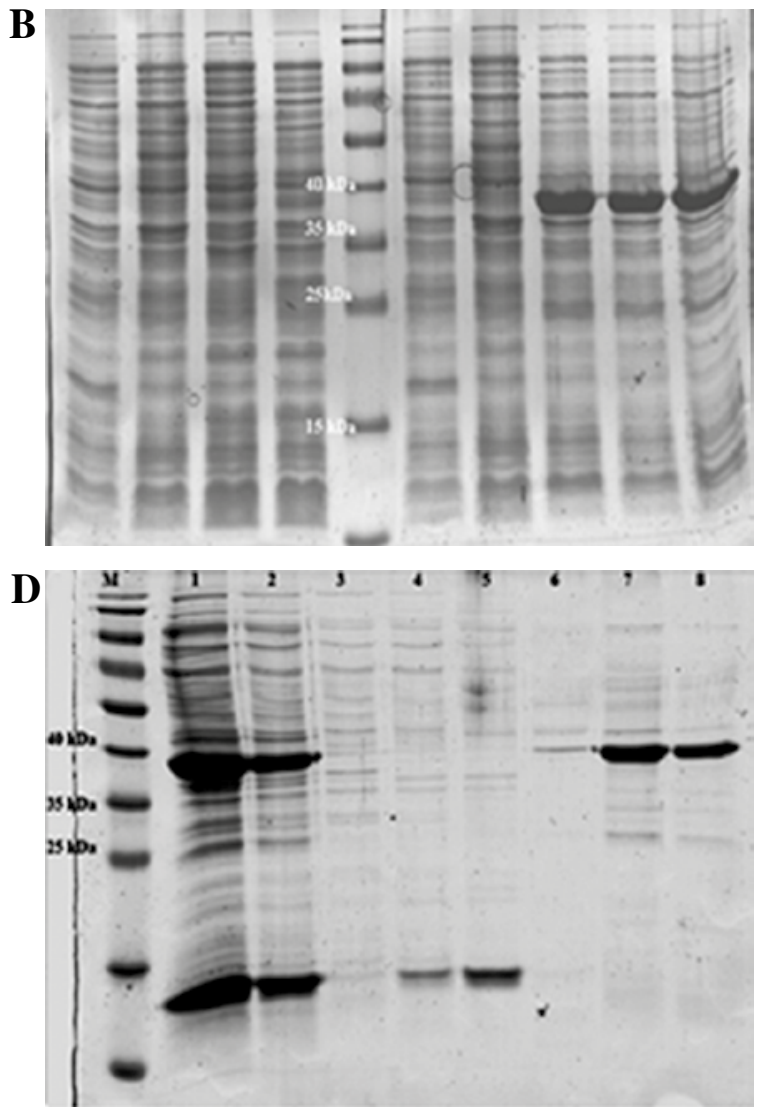

Fig. 1. Amplification, cloning, and confirmation of the OMP28 precursor gene. A) Confirmation of the cloning of B) melitensis Rev1 OMP28 precursor gene into pETSUMO expression vector. M: DNA size marker, (lanes 1-3); OMP28 precursor gene. B) Expression of His-SUMO-OMP28 precursor fusion protein by using 1 M IPTG at different hours (lane 1); baseline/hour zero (lane 2-4); $6^{\text {th }}-7^{\text {th }}$ hours IPTG (-). M: marker (lane 5); hour zero (lane 6); $1^{\text {st }}$ hour, (lane $7-9$ ); $6^{\text {th }}-8^{\text {th }}$ hours IPTG (+). C) SDS-PAGE analysis of the protein extracts made with denatured and native methods (lane 1-2); supernatant obtained by native lysis (lane 3-4); total cell lysates, obtained with the native lysis. M: marker (lane 5); total cell lysate obtained by denatured lysis (lane 6); the pellet of lysis obtained with the native, applying denaturing lysis. D) SDS-PAGE analysis of protein purification step by Ni-NTA affinity column (lane 1-2); total cell lysate (lane 3); binding fraction (lane 4-6); washing fraction (lane 7-8); elution fraction 
IPTG concentration of $1 \mathrm{mM}$ and $6 \mathrm{~h}$ of incubation with shaking following transfection induction were at the desired level for the expression of the protein. Results indicated that E. coli BL21 (DE3) harbouring His-SUMOOMP28 precursor expressed the His-SUMO-OMP28 precursor protein with a molecular weight of approximately $40 \mathrm{kDa}$ (Fig. 1B).

Protein solubility is an important issue, so we determined the solubility via lysing the cells by treating native buffer containing lysozyme on ice followed by a sonication step. Collected lysate was centrifuged at 10,000 rpm for $30 \mathrm{~min}$, separating the soluble protein components in supernatant and insoluble material in a cell pellet. The majority of the expressed His-SUMO-OMP28 precursor protein was found in the insoluble fraction accumulated as insoluble aggregates called inclusion bodies. The extraction and purification of those aggregates requires a denaturing environment created by $8 \mathrm{M}$ urea. Under such conditions, about $30 \mathrm{mg}$ protein is purified from 1 litre of induced culture (Fig. 1C).

Native and urea-rich conditions were applied successfully for purification. Protein of interest tightly bound to Ni-NTA agarose was eluted using $\mathrm{pH}$ gradient. After repetitive cycles of washing and elution, the products were analysed by SDS-PAGE. Eventually the expressed protein was purified with an efficiency greater than $90 \%$ (Fig. 1D).

Following the purification by Ni-NTA affinity chromatography, the protein was eluted from polyacrylamide gel and Western blot analysis was carried out. A single band corresponding to a size of approximately $40 \mathrm{kDa}$ matched to the recombinant His-SUMO-OMP28 precursor protein (Fig. 1C and Fig. 2).

In the same cloning reaction, an additional protein of size $13 \mathrm{kDa}$ from the vector including the 6xHis-SUMO tag was co-expressed with the complete OMP28 precursor protein. When SUMO is fused to the N-terminus of OMP28 precursor protein, cleavage by SUMO protease resulted in the production of native proteins (Fig. 3).

\section{iELISA on the basis on OMP28 precursor protein resembles a reliable immunoassay in comparison with standard agglutination tests}

The efficiency of purified OMP28 precursor was studied in an indirect enzyme-linked immunosorbent assay (iELISA) for diagnosis of brucellosis in samples collected from a rural area. Employing confirmed negative and positive serum samples for the disease, it has been documented that OMP28 precursor is strongly immunoreactive to Brucella-infected human sera. Sixty samples were tested by iELISA developed on the basis of OMP28 precursor antigen, and the results were evaluated along with RBPT results. iELISA assay was considered positive when the mean absorbance value was greater than four SDs above the mean value for the healthy controls. The mean absorbance value and SD for the healthy sub-

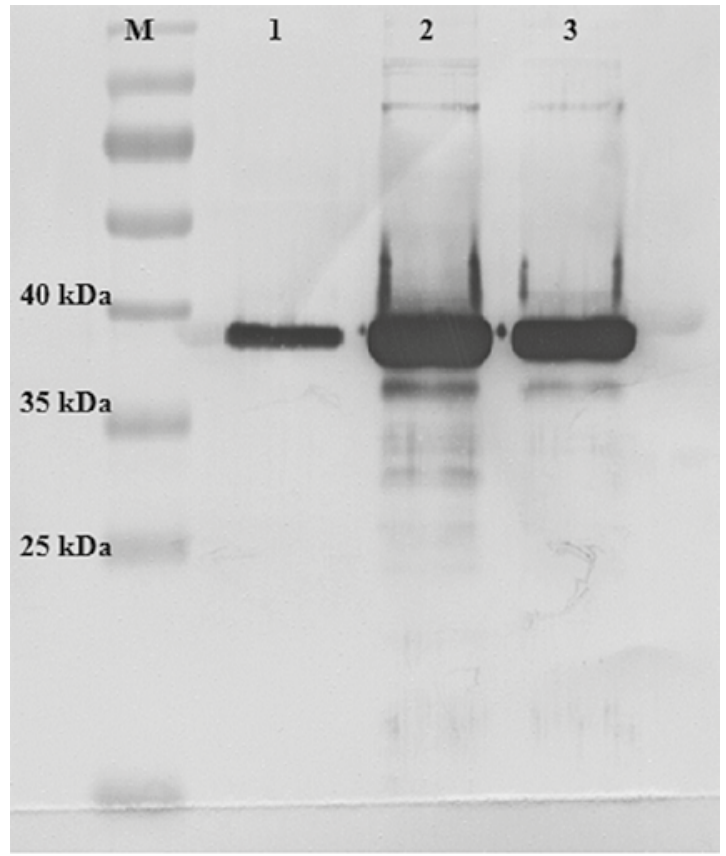

Fig. 2. Western blot analysis of the recombinant HisSUMO-OMP28 precursor protein. M: marker. Western blot analysis of the whole cell lysate of non-purification (lane 1), and protein elution fraction (lane 2-3) by mouse monoclonal anti-His-tag antibody. The single band shows the expression of His-SUMO-OMP28 precursor protein

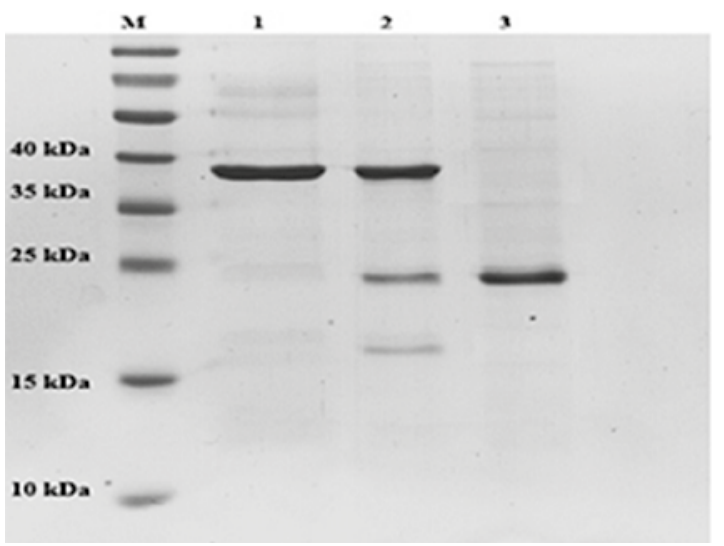

Fig. 3. SDS-PAGE analysis of cutting and purification steps of His-SUMO-OMP28 precursor protein by sumo protease. M: marker (lane 1); purified His-SUMOOMP28 precursor protein (lane 2); the products generated by cutting of His-sumo-OMP28 recombinant protein with SUMO protease; the top band represents uncut recombinant His-Sumo-OMP28 fusion protein at around $40 \mathrm{kDa}$, the middle one is OMP28 precursor protein at around $25 \mathrm{kDa}$, and the bottom band represents His-SUMO protein (lane 3); native OMP28 precursor protein attained after Ni-NTA affinity column application of SUMOprotease-treated protein product 
Table 1. Reliability comparison: new iELISA and RBAT

\begin{tabular}{lccc}
\hline \multirow{2}{*}{$\begin{array}{l}\text { OMP28 } \\
\text { precursor } \\
\text { iELISA }\end{array}$} & \multicolumn{3}{c}{ Rose Bengal agglutination test } \\
\cline { 2 - 4 } & Brucellosis (+) & Brucellosis (-) & Total \\
\hline Brucellosis (+) & 29 & 1 & 30 \\
\hline Brucellosis (-) & 4 & 26 & 30 \\
\hline Total & 33 & 27 & 60 \\
\hline
\end{tabular}

jects in the study was $0.17 \pm 0.04$, and a sample was considered positive when the mean absorbance of the measurements was greater than 0.33. Recombinant OMP28 precursor antigen-based ELISA has shown sensitivity of $87.8 \%$, specificity of $96.2 \%$, positive predictive value of $96.6 \%$, negative predictive value of $78.78 \%$, and accuracy of $91.6 \%$ (Table 1).

\section{Discussion}

Brucellosis is a formidable zoonotic infection caused by a bacterium equipped with atypical virulence factors. Due to its wide distribution in both animals and humans, the disease is recognised as an emerging public health problem, especially in developing countries. Brucellosis has a huge economic impact and serious medical consequences. Thus, studies aimed at early detection and prevention of the disease, including the establishment of new diagnostic tools, have been made for recent years. Diagnosis of the disease is generally carried out by bacterial isolation and characterisation from blood samples. The procedures currently used in the serological diagnosis of brucellosis are complement fixation test, Rose Bengal plate test, standard tube agglutination test, and milk ring test assay $[15,33]$.

The drawbacks of primary cell culture are slow growth rates of bacteria delaying both the diagnosis and the treatment for days, and low sensitivity $[15,33]$. Similarly, serological tests, which are established based on the principle of the detection of primary antibodies produced against LPS located on bacterial cell membrane, suffer from high rates of false-positivity due to cross-reactivity issues with other Gram-negative bacteria [13-15]. Therefore, many research studies have shared a major goal in immunology, which is the identification of an alternative antigenic target instead of LPS, to overcome the drawbacks of LPS antigen and to increase the sensitivity of serological tests $[13-15,17]$. The present study aimed to elucidate if the full-length recombinant OMP28 precursor protein of B. melitensis Rev1 displays immunoreactivity strong enough to establish an ELISA-based diagnosis.

Successful amplification followed by efficient cloning and steady expression of a target gene by utilising appropriate vectors are the core steps in recombinant protein synthesis. The literature includes many recent studies com- monly employing two separate vectors designed for cloning and expression in order to achieve stable cloning of the genetic material and successful initiation and maintenance of the expression of recombinant protein $[34,35]$. In these and similarly conducted studies, restriction enzymes have been extensively used from delivery of PCR products into the cloning vector to the transfer of the cloned gene into the expression vector. In the present study, we successfully used pETSUMO cloning-expression vector employing direct $\mathrm{A} / \mathrm{T}$ cloning method enabling us to reduce the number of time-consuming steps in the whole extraction process. There is general consensus that the use of microbial systems in recombinant protein synthesis was one of the turning points for biological and immunological studies. In this machinery, the choice of appropriate vectors is important and greatly influences the success of the protein synthesis. The major things to be considered are the structure of the vector with a number of combinations of replicons, the type of selection markers, carrying strong promoters, multiple cloning sites (enough to manipulate), and inclusiveness of fusion-protein removal strategies. We have chosen and employed pETSUMO cloning-expression vector, and succeeded with the downstream steps eventually achieving a good amount of our target recombinant protein.

Different extraction-lysis solutions have been used to purify expressed proteins. In some studies, protein extraction was made via native extraction methods $[12,36$, 37], while others used denaturing methods. We preferred to use the denaturing lysis method because we observed that the expressed recombinant protein was in cytoplasm. Our data indicated that the major localisation of the expressed protein was inside the inclusion bodies within the pellet of cell lysate in the cells. Chaudhuri et al. [12] achieved the production of recombinant $B$. melitensis $16 \mathrm{M}$ rOMP28 protein as $1.2-12 \mathrm{mg} / \mathrm{l}$ in native conditions and $90-150 \mathrm{mg} / \mathrm{l}$ in denaturing conditions, by testing various vector and expression procedures. The most important factor determining the increased efficiency in protein retrieval was suggested to be the use of $\beta$-mercaptoethanol, a strong reducing agent. We achieved a total of $30 \mathrm{mg} / \mathrm{l}$ recombinant protein production in this study without using $\beta$-mercaptoethanol, due to its harmful effect on the Ni-NTA column we used in the purification step. In future, we anticipate that it may be possible to increase protein retrieval if a column not sensitive to $\beta$-mercaptoethanol is used.

Recombinant Brucella proteins targeted in previous research studies have generally been produced with $N$ - or $C$-terminal polyhistidine sequence, called His-tag [14, 17, $19,39]$. Due to the tag portions, the proteins synthesised in this way usually lack their natural (natively folded) forms. In the present study, recombinantly produced protein was treated with sumo proteases, and His-SUMO tags were removed to allow the recombinant protein to assume its native form.

Establishment of an advanced, efficient diagnostic tool for brucellosis is critical for both preventing the spread 
of the disease and reducing diagnosis and treatment costs. ELISA-based tests seem more appropriate to obtain accurate and fast diagnosis in chronic and complex clinical situations when compared to other diagnostic modalities [40]. In order to establish a basis for new ELISA tests, various Brucella proteins recombinantly synthesised using genomic databases and their diagnostic potentials have been determined [14, 17, 19, 39].

In a study on $B$. abortus strain 99 , an avidin-biotin ELISA (A-B ELISA) kit was produced for the diagnosis of cattle brucellosis using bacterial lipopolysaccharide as the primary antigen [33]. Infected and healthy cattle serum samples, 500 for each group, were tested, and ELISA produced successful results with $98.8 \%$ specificity and $98.2 \%$ sensitivity. Cassataro et al. recombinantly expressed OMP31 protein of $B$. melitensis strain $16 \mathrm{M}$ through cloning to Pet22+ vector and assayed the immunodiagnostic potential by indirect ELISA method [5]. Seventy-four humans, 57 sheep, and 47 dogs with Brucella infection were included in the study, and the obtained serum samples were assayed. The sensitivity of rOMP31 protein ELISA in humans, sheep, and dogs were, respectively, 47\%, 59\%, and 67\%. B. melitensis $\mathrm{s} 16 \mathrm{M}$ rOMP28 protein was used in another study utilising pPROExHTb vector for cloning. Chaudhuri et al. [12] synthesised the recombinant protein with $N$-terminal His-tag, and the diagnostic value of this protein in brucellosis was evaluated in serum samples of various infected animals by ELISA, achieving high sensitivity and specificity at around $90 \%$, which is similar to the results of the present study. In a recent study from China, involving 35,000 new Brucella cases that arose in 2010, BP26 protein from B. melitensis vaccine strain M5-90 was recombinantly produced, and the characterisation of the protein and the identification of its immunogenic epitopes were determined using newly synthesised monoclonal anticors. rBP26 and NMP peptides of the protein with highly immunogenic epitope sites were tested by ELISA and demonstrated $70 \%$ and $90 \%$ specificity, respectively [18]. OMP28 of B. abortus was cloned via a pMAL expression system by Lim et al., and rOMP28ELISA was developed and tested on bovine brucellosis yielding successful results with sensitivity, specificity, and accuracy of 96.7, 95.4, and 96.2\%, respectively [41]. Multiple recombinant OMPs have been used as a single antigenic coating on an indirect ELISA system in two consecutive studies conducted by Ahmed et al. [42, 43]. rOMP25, rOMP28, and rOMP31 of B. melitensis were successfully cloned via a prokaryotic pET-32 Ek/LIC system and used as the single major antigenic target to distinguish vaccinated and infected animals by serologically achieving the sensitivity-specificity ratios of $100-100 \%$ for an experimental study on mice and $94.44-84.62 \%$ for caprine brucellosis. In another study designed similarly on Korean cattle brucellosis, rOMPs 10,19 , and 28 of B. abortus were used in combination. The achieved ELISA results have given rise to highly encouraging outcomes of reactivity tests with high sensitivity, specificity, and accuracy [44]. In the present study, we developed an ELISA test using recombinant production of a membrane protein, OMP28 precursor protein of $B$. melitensis Rev1 lacking a tag portion in a native way, and achieved promising results with high sensitivity, specificity, and accuracy rates in human brucellosis.

In conclusion, recombinant production and purification of the immunodominant OMP28 precursor protein has been achieved successfully in a one step process with efficient outcome. This study demonstrated that indirect ELISA established on the recombinant OMP28 precursor protein yielded high sensitivity and specificity for the detection of anti-Brucella antibodies in human sera collected from different hospitals in our province. Hence, it can be concluded that recombinant $B$. melitensis OMP28 precursor could be used as a protein antigen for diagnosis of brucellosis in humans. The same antigen could also be potentially used in diagnostic tests in animals suffering the same disease, such as sheep and goat, if further studies were conducted in those samples. This study has also shown that immunoreactive OMP28 precursor protein of B. melitensis Rev1 could be expressed at a high level in the $E$. coli system and further purified to almost homogeneity in a single step.

\section{Acknowledgements}

We thank Dr. Hakim Celik for his critical review of the manuscript.

All protocols in the study were approved by the Local Research Ethics Committee at Harran University in compliance with the principles of the Declaration of Helsinki. Ethics Committee Approval Number: B.30.2.H RÜ.0.20.05.00.050.01.04-227. Funding: Harran University Institutional Scientific Research Support Fund HUBAK_26540.

\section{The authors declare no conflict of interests.}

\section{References}

1. Matyas Z, Fujikura T (1984): Brucellosis as a world problem. Dev Biol Stand 56: 3-20.

2. Young EJ (1983): Human brucellosis. Reviews of Infectious Diseases 5: 821-842.

3. Young EJ (1995): An overview of human brucellosis. Clin Infect Dis 21: 283-289; quiz 290.

4. Moreno E, Cloeckaert A, Moriyón I (2002): Brucella evolution and taxonomy. Vet Microbiol 90: 209-227.

5. Cassataro J, Pasquevich K, Bruno L, et al. (2004): Antibody reactivity to OMP31 from Brucella melitensis in human and animal infections by smooth and rough Brucellae. Clin Diagn Lab Immunol 11: 111-114.

6. Corbel MJ (1997): Brucellosis: an overview. Emerg Infect Dis 3: 213-221.

7. Morgan WJ, MacKinnon DJ, Lawson JR, et al. (1969): The rose bengal plate agglutination test in the diagnosis of brucellosis. Vet Rec 85: 636-641. 
8. Ruiz-Mesa JD, Sánchez-Gonzalez J, Reguera JM, et al. (2005): Rose Bengal test: diagnostic yield and use for the rapid diagnosis of human brucellosis in emergency departments in endemic areas. Clin Microbiol Infect 11: 221-225.

9. Nielsen K, Smith P, Yu WL, et al. (2007): Salmonella enterica Serotype Urbana Interference with Brucellosis Serology. J Immunoassay Immunochem 28: 289-296.

10. Vahedi F, Talebi AF, Ghorbani E, et al. (2011): Isolation, cloning and expression of the Brucella melitensis OMP31 gene. Iran J Vet Res 12: 156-162.

11. Weynants V, Tibor A, Denoel PA, et al. (1996): Infection of cattle with Yersinia enterocolitica O:9 a cause of the false positive serological reactions in bovine brucellosis diagnostic tests. Vet Microbiol 48: 101-112.

12. Chaudhuri P, Prasad R, Kumar V, et al. (2010): Recombinant OMP28 antigen-based indirect ELISA for serodiagnosis of bovine brucellosis. Mol Cell Prob 24: 142-145.

13. Büyüktanir Ö, Genç O, Yurdusev N. (2011): Production, Purification and Characterization of the Recombinant Brucella abortus rP17 Protein. Kafkas Univ Vet Fak 17: 135-140.

14. Farahi F, Asli E, Mobarez AM, et al. (2012): Recombinant Brucella abortus outer membrane protein 19 (rOMP19) significantly stimulates splenic lymphocytes of immunized BALB/c mice. Afr J Microbiol Res 6: 4128-4131.

15. Thavaselvam D, Kumar A, Tiwari S, et al. (2010): Cloning and expression of the immunoreactive Brucella melitensis 28 kDa outer-membrane protein (OMP28) encoding gene and evaluation of the potential of OMP28 for clinical diagnosis of brucellosis. J Med Microbiol 59: 421-428.

16. Fu S, Xu J, Li X, et al. (2012): Immunization of Mice with Recombinant Protein CobB or AsnC Confers Protection against Brucella abortus Infection. PLoS One 7: e29552.

17. Eoh H, Jeon B-Y, Kim Z, et al. (2010): Expression and validation of D-erythrulose 1-phosphate dehydrogenase from Brucella abortus: a diagnostic reagent for bovine brucellosis. J Vet Diagn Invest 22: 524-530.

18. Qiu J, Wang W, Wu J, et al. (2012): Characterization of periplasmic protein BP26 epitopes of Brucella melitensis reacting with murine monoclonal and sheep antibodies. PloS One 7: e34246.

19. Yang Y, Yin J, Guo D, et al. (2011): Immunization of mice with recombinant S-adenosyl-L-homocysteine hydrolase protein confers protection against Brucella melitensis infection. FEMS Immunol Med Microbiol 61: 159-167.

20. Kumar S, Tuteja U, Kumar A, et al. (2008): Expression and purification of the $26 \mathrm{kDa}$ periplasmic protein of Brucella abortus: a reagent for the diagnosis of bovine brucellosis. Biotechnol Appl Biochem 49: 213-218.

21. Cloeckaert A, Jacques I, Limet JN, et al. (1995): Immunogenic properties of Brucella melitensis cell-wall fractions in BALB/c mice. J Med Microbiol 42: 200-208.

22. Cassataro J, Pasquevich KA, Estein SM, et al. (2007): A DNA vaccine coding for the chimera BLSOMP31 induced a better degree of protection against B. ovis and a similar degree of protection against B. melitensis Rev.1 vaccination. Vaccine, 25: 5958-5967.

23. Lindler LE, Hadfield TL, Tall BD, et al. (1996): Cloning of a Brucella melitensis group 3 antigen gene encoding OMP28, a protein recognized by the humoral immune response during human brucellosis. Infect Immun 64: 2490-2499.

24. Jubier-Maurin V, Boigegrain RA, Cloeckaert A, et al. (2001): Major outer membrane protein OMP25 of Brucella suis is involved in inhibition of tumor necrosis factor alpha production during infection of human macrophages. Infect Immun 69: 4823-4830.

25. Letesson JJ, Tibor A, van Eynde G, et al. (1997): Humoral immune responses of Brucella-infected cattle, sheep, and goats to eight purified recombinant Brucella proteins in an indirect enzyme-linked immunosorbent assay. Clin Diagn Lab Immunol 4: 556-564.

26. Dubray G, Bézard G (1980): Isolation of three Brucella abortus cell-wall antigens protective in murine experimental brucellosis. Annales de recherches vétérinaires. Ann Vet Res 11: 367-373.

27. Liu WX, Hu S, Qiao ZJ, et al. (2011): Expression, purification, and improved antigenic specificity of a truncated recombinant bp26 protein of Brucella melitensis M5-90: a potential antigen for differential serodiagnosis of brucellosis in sheep and goats. Biotechnol Appl Biochem 58: 32-38.

28. Laemmli UK (1970): Cleavage of Structural Proteins during the Assembly of the Head of Bacteriophage T4. Nature 227: 680-685.

29. Towbin H, Staehelin T, Gordon J (1979): Electrophoretic transfer of proteins from polyacrylamide gels to nitrocellulose sheets: procedure and some applications. Proc Natl Acad Sci U S A 76: 4350-4354.

30. Bradford MM (1976): A rapid and sensitive method for the quantitation of microgram quantities of protein utilizing the principle of protein-dye binding. Anal Biochem 72: 248-254.

31. Wang Q, Min C, Yan T, et al. (2011): Production of glutamine synthetase in Escherichia coli using SUMO fusion partner and application to 1-glutamine synthesis. World J Microbiol Biotechnol 27: 2603-2610.

32. Fawcett T (2006): An introduction to ROC analysis. Pattern Recognition Letters 27: 861-874.

33. Mantur BG, Mangalgi SS (2004): Evaluation of conventional castaneda and lysis centrifugation blood culture techniques for diagnosis of human brucellosis. J Clin Microbiol 42: 43274328.

34. González M, Andrews E, Folch H, et al. (2009): Cloning, expression and immunogenicity of the translation initiation factor 3 homologue of Brucella abortus. Immunobiology 214: 113-120.

35. Renukaradhya GJ, Isloor S, Crowther JR, et al. (2001): Development and field validation of an avidin-biotin enzyme-linked immunosorbent assay kit for bovine brucellosis. Rev Sci Tech 20: 749-756.

36. Cassataro J, Delpino MV, Velikovsky CA, et al. (2002): Diagnostic usefulness of antibodies against ribosome recycling factor from Brucella melitensis in human or canine brucellosis. Clin Diagn Lab Immunol 9: 366-369.

37. Zygmunt MS, Baucheron S, Vizcaino N, et al. (2002): Single-step purification and evaluation of recombinant BP26 protein for serological diagnosis of Brucella ovis infection in rams. Vet Microbiol 87: 213-220.

38. Ding XZ, Bhattacharjee A, Nikolich MP, et al. (2005): Cloning, expression, and purification of Brucella suis outer membrane proteins. Protein Expr Purif 40: 134-141.

39. Pasquevich KA, Estein SM, García Samartino C, et al. (2009): Immunization with recombinant Brucella species outer membrane protein OMP16 or OMP19 in adjuvant induces specific CD4+ and CD8+ T cells as well as systemic and oral protection against Brucella abortus infection. Infect Immun 77: 436-445.

40. George FA, Mireille MK, Layla GF, et al. (2005): Evaluation of the PANBIO Brucella Immunoglobulin $\mathrm{G}(\mathrm{IgG})$ and $\operatorname{IgM}$ 
Enzyme-Linked Immunosorbent Assays for Diagnosis of $\mathrm{Hu}-$ man Brucellosis. Clin Diagn Lab Immunol 12: 1334-1335.

41. Lim J, Kim D, Lee J, et al. (2012): Evaluation of recombinant $28 \mathrm{kDa}$ outer membrane protein of Brucella abortus for the clinical diagnosis of bovine brucellosis in Korea. J Vet Med Sci 74: 687-691.

42. Ahmed IM, Khairani-Bejo S, Hassan L, et al. (2014): Recombinant outer membrane proteins (rOMPs) of Brucella melitensis as a potential serological marker for diagnosis of caprine brucellosis. J Anim Vet Adv 13: 231-235.

43. Ahmed IM, Khairani-Bejo S, Hassan L, et al. (2015): Serological diagnostic potential of recombinant outer membrane proteins (rOMPs) from Brucella melitensis in mouse model using indirect enzyme-linked immunosorbent assay. BMC Vet Res 11: 275.

44. Simborio HLT, Lee JJ, Reyes AWB, et al. (2015): Evaluation of the combined use of the recombinant Brucella abortus OMP10, OMP19 and OMP28 proteins for the clinical diagnosis of bovine brucellosis. Microb Pathog 83: 41-46. 